\title{
An unusual case of interstitial pregnancy: a case report
}

\author{
Nikhil Sebastian ${ }^{1 *}$, Abhishek Radhakrishnan', Vennila Murugesan²
}

\author{
${ }^{1}$ Department of Reproductive Medicine, ${ }^{2}$ Department of Fetal Medicine, Kinder Women's Hospital and Fertility \\ Centre, Cherthala, Kerala, India
}

Received: 17 January 2021

Accepted: 11 February 2021

\section{*Correspondence:}

Dr. Nikhil Sebastian,

E-mail: nikhilsebastian571@gmail.com

Copyright: $\odot$ the author(s), publisher and licensee Medip Academy. This is an open-access article distributed under the terms of the Creative Commons Attribution Non-Commercial License, which permits unrestricted non-commercial use, distribution, and reproduction in any medium, provided the original work is properly cited.

\begin{abstract}
Ectopic pregnancy (EP) has been found to be a common cause of morbidity, and on occasion, mortality among women in the reproductive age groups. The incidence of EP is 1-2\% of all pregnancies. 93-97\% of EP are tubal with the interstitial type consisting only 3-4\%. A 31-year-old female patient with primary infertility underwent IVF (In Vitro Fertilization). Pregnancy was confirmed by $\beta \mathrm{HCG}$ (beta human chorionic gonadotropin). Her ultrasonography reported a mass in the right cornual region. The uterine cavity was empty. Laparoscopy was performed followed by resection of the right cornua with tubes. Histopathology report confirmed the diagnosis of Interstitial Pregnancy (IP). The patient had an uneventful post-operative period and was discharged the next day. EP is a common complication seen in cases undergoing IVF, and IP is a rare form of EP. Hence, early diagnosis and prompt intervention is required to avoid a potentially life-threatening situation.
\end{abstract}

Keywords: Ectopic pregnancy, Interstitial pregnancy, In vitro fertilization, Laparoscopy

\section{INTRODUCTION}

Ectopic pregnancy (EP) has been found to be a common cause of morbidity and occasionally mortality among women in the reproductive age group. An EP occurs when the fertilized ovum implants outside the normal uterine cavity. ${ }^{1}$ The incidence of EP is $1-2 \%$ of all pregnancies. 93-97\% of EP are tubal with the interstitial type constituting only $3-4 \% .^{2}$ Hence, interstitial pregnancy (IP) is a rare condition but is associated with difficulty in diagnosis and has higher complication rates.

The various risk factors for IP include: pelvic inflammatory disease, previous tubal surgery, previous $\mathrm{EP}$, and factors associated with assisted reproductive techniques like multiple embryo transfer, or embryos transferred in close proximity to the uterine cornua and excessive pressure of the syringe during embryo transfer. The only risk factor exclusively associated to IP is bilateral tubal occlusion. In patients without bilateral tubal occlusion, peri tubal or intratubal adhesions due to endometriosis can also be a risk factor. ${ }^{3}$ IVF is associated with EP risk of 2-5\% and it may be higher than this where there is tubal disease. ${ }^{4}$ Before the first IVF live birth of Lewis Brown, the first IVF pregnancy was a tubal EP.

The classical triad of EP include amenorrhea, followed by vaginal bleeding and abdominal pain. Some patients may have no symptoms and may present as a surgical emergency. Since IP occurs within the interstitial portion of the fallopian tube, it has the potential to grow to large sizes compared to other types of EP. Hence, the patient may present to us in a massive potentially life-threatening haemorrhagic shock. The mortality rate of EP was reported to be $0.14 \%$ while that for IP was reported to be nearly 15 times higher at $2-2.5 \%$.

IP remains to be one of the most difficult gestations to diagnose. Transvaginal ultrasonography is a useful tool for locating the pregnancy. The ultrasound findings to diagnose IP are the eccentric location of the gestational 
sac proximal to the uterine horn, the presence of an interstitial line (echogenic line that extends from the most superior and lateral aspect of the endometrium to the middle portion of the mass or interstitial sac), failure to see the myometrium completely surrounding the sac and failure of the gestational sac to communicate with the endometrium6. In cases with rupture, hemoperitoneum can be observed. Other imaging modalities include MRI and 3D USG. A 3D USG can be used for precisely locating the interstitial gestational sac, and hence differentiating it from eccentrically located intrauterine gestational sac. MRI can be used in non-urgent cases when the USG findings are inconclusive. It has the ability to visualize the whole uterus and thus identify the exact site of implantation.

\section{CASE REPORT}

A 31-year-old female patient with 4 years history of primary infertility underwent IVF for unexplained infertility. Her 18 th day $\beta H C G$ was positive. An ultrasonography at 7 weeks showed anteverted uterus and a mass in the myometrial region located at the right cornual region measuring $2.4 \times 2.3 \mathrm{~cm}$ with $12 \times 9 \mathrm{~mm}$ gestational sac (Figure 1). Cardiac activity was present and no free fluid in the cul de sac. The diagnosis of IP was hypothesized. On admission, the patient was clinically and hemodynamically stable. Her $\beta \mathrm{HCG}$ on admission was $5861.77 \mathrm{U} / \mathrm{L}$. The case was discussed with the patient and bystanders. They opted for resolution of the condition through laparoscopy. The intra operative findings were as follows: (Figure 2) uterus was the seat of right IP.

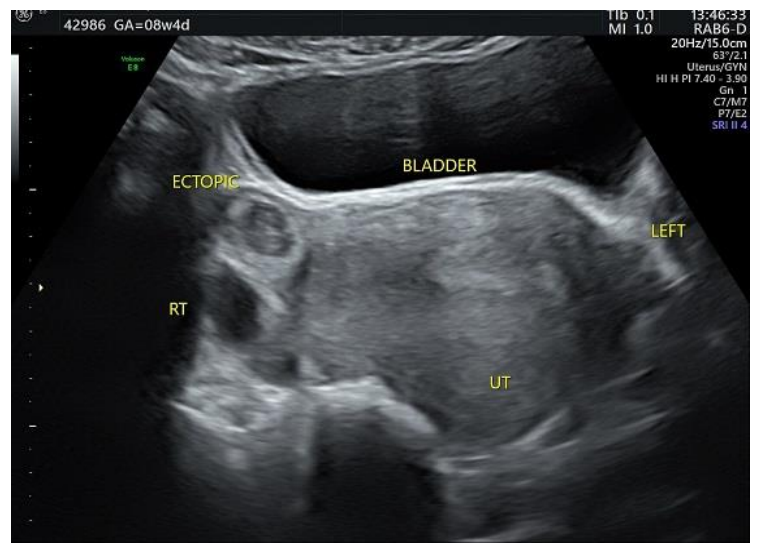

Figure 1: Transabdominal ultrasound scan showing empty uterine cavity and ectopic mass in the right cornual region.

Right tube was unhealthy and right ovary was normal. Left tube was adherent to pelvic side wall and the left ovary was normal. Right cornua with tubes were coagulated and removed (Figure 3). The specimen was sent for histopathological examination. The patient recovered without any surgical complications and was discharged from the hospital the next day. Her histopathology report confirmed the diagnosis of IP.

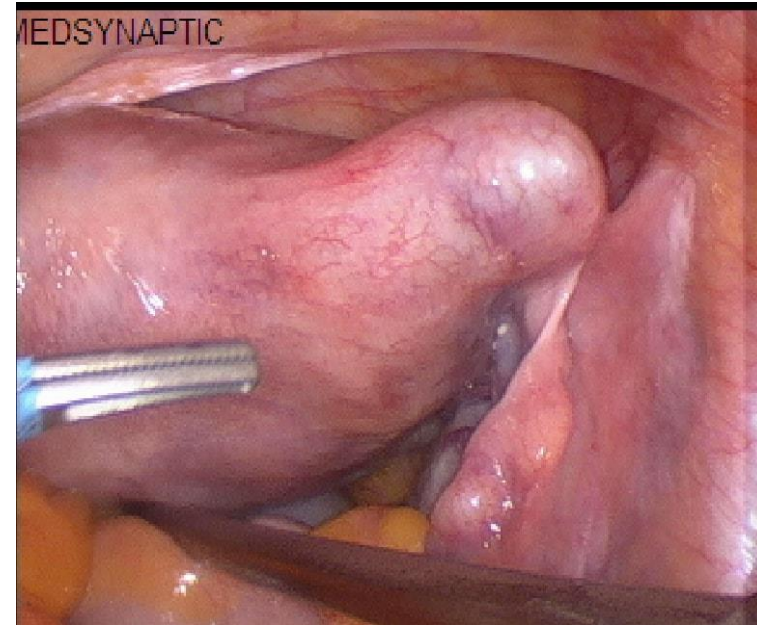

Figure 2: Intra operative finding showing right interstitial pregnancy.

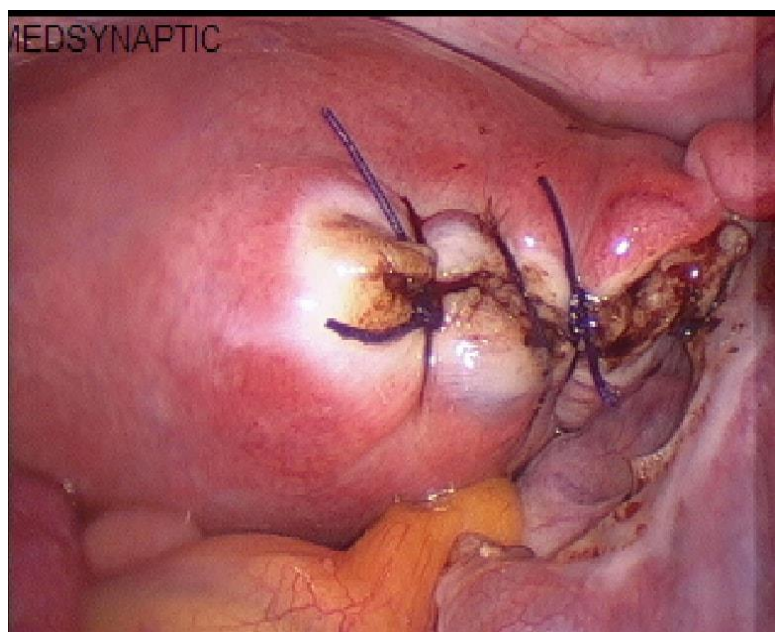

Figure 3: Post-operative picture after removal of right cornual region with the tubes.

The aforementioned case of IP describes a clinical picture similar to that in literature (occurring between 6 and 8 weeks). ${ }^{7}$ The diagnosis of EP in our case was done by the proof of pregnancy by $\beta \mathrm{HCG}$, USG features of IP, laparoscopy and histopathology report.

\section{DISCUSSION}

EP is a condition which can be managed surgically, medically or expectantly. IP is often confused with cornual pregnancy. The literature differentiates between the terms by stating that a cornual pregnancy is found in the endometrium of the cornua of a bicornuate/ unicornuate uterus, or even outside the endometrial cavity, while an IP is found within the union of the uterus and the proximal portion of the fallopian tube. ${ }^{8}$ As the first line of treatment, RCOG recommends methotrexate in patients with $\beta \mathrm{HCG}<5000 \mathrm{IU} / \mathrm{ml}$, EP $<3.5 \mathrm{~cm}$, no cardiac activity with minimal symptoms. However, in this case, a surgical approach was preferred as the $\beta \mathrm{HCG}$ levels were high and there was cardiac activity. 
In the earlier days, the treatment of IP was laparotomy, hysterectomy or cornual resection. All these procedures were associated with frequent complications and an increased morbidity rate. ${ }^{9}$ However, now a days, a more conservative approach is preferred such a laparoscopy and cornuostomy. These procedures are associated with persistent EP in about $27 \%$ cases. Hence, rigorous follow up during the post-operative period is required. Furthermore, patients should undergo cesarean section in future pregnancies because of the risk of uterine rupture. ${ }^{10}$ Persistent trophoblastic activities can be treated successfully with methotrexate. Hence IP has higher mortality rate compared to other types of EP and highlights the need for early diagnosis. In the case described previously, a case of IP is presented. The diagnosis of IP was carried out by $\beta$ HCG test, TVS characteristics of IP and by laparoscopy.

\section{CONCLUSION}

IP is rare presentation of EP. A delay in diagnosis can lead to high maternal morbidity and mortality. However, early diagnosis and prompt treatment can prevent life threatening complications like massive hemorrhage and uterine rupture. If a 3D scan is available, it should be used as it increases the diagnostic accuracy. The patient should be counselled regarding the persistence of EP, recurrence rate as well as the risks associated with future pregnancies.

Funding: No funding sources Conflict of interest: None declared Ethical approval: Not required

\section{REFERENCES}

1. Walker JJ. Ectopic pregnancy. Clin Obstet Gynecol. 2007;50:89-99.

2. Kirsch JD, Scoutt LM. Imaging of ectopic pregnancy. Applied Radiol. 2010;10-25.

3. Grindler NM, Ng J, TocceK, Alvero R. Considerations for management of interstitial ectopic pregnancies: two case reports. J Med Case Rep 2016;10:6.

4. Steptoe PC; Edwards RG. Reimplantation of human embryo with subsequent tubal pregnancy. Lancet. 1976;1:880-2.

5. Tulandi T, Al-Jaroudi D. Interstitial pregnancy: results generated from the Society of Reproductive Surgeons registry. Obstet Gynecol. 2004;103:47-50.

6. Levine D: Ectopic pregnancy. Radiology. 2007,245:385-97.

7. Choi YS, Eun DS, Choi J, Shin KS, Choi JH, Park HD. Laparoscopic cornuotomy using a temporary tourniquet suture and diluted vasopressin injection in interstitial pregnancy. Fertil Steril. 2009,91:1933-7.

8. Wang J, Huang D, Lin X, Saravelos SH, Chen J. Incidence of interstitial pregnancy after in vitro fertilization/embryo transfer and the outcome of a consecutive series of 38 cases managed by laparoscopic cornuostomy or cornual repair. J Minim Invasive Gynecol. 2016;9:134-5.

9. Singh N, Tripathi R, Mala YM, Batra A. Diagnostic dilemma in cornual pregnancy-3D ultrasonography may Aid!! J Clin Diagn Res 2015;9:12-3.

10. Surbone A, Cottier O, Vial Y, Francini K, Hohlfeld P. Interstitial pregnancies diagnosis and management: an eleven cases series. Swiss Med Wkly 2013;143:13736.

Cite this article as: Sebastian N, Radhakrishnan A, Murugesan V. An unusual case of interstitial pregnancy: a case report. Int J Reprod Contracept Obstet Gynecol 2021;10:1229-31. 